\title{
In vitro - In vivo Correlation (IVIVC) of Immediate Release (IR) Levofloxacin Tablet
}

\section{Maruf Mohammad Akbor ${ }^{1}$, Rebeka Sultana ${ }^{1}$, Ashik Ullah ${ }^{1}$, Mohammad Abul Kalam Azad ${ }^{2}$, A. H. M. Mahbub Latif ${ }^{3}$ and Abul Hasnat ${ }^{1}$}

\author{
${ }^{1}$ Department of Clinical Pharmacy and Pharmacology, Faculty of Pharmacy, University of Dhaka, \\ Dhaka-1000, Bangladesh \\ ${ }^{2}$ Department of Pharmaceutical Technology, Faculty of Pharmacy, University of Dhaka, \\ Dhaka-1000, Bangladesh \\ ${ }^{3}$ Institute of Statistical Research and Training, University of Dhaka, Dhaka-1000, Bangladesh
}

\begin{abstract}
The aim of this study was to examine the in vitro - in vivo correlation (IVIVC) of two immediate release formulations of levofloxacin $250 \mathrm{mg}$ film coated tablet. In vitro release data were obtained for each formulation by using the USP apparatus II, in $0.1 \mathrm{~N} \mathrm{HCl} \mathrm{of} \mathrm{pH}$ 2.0. Twelve healthy subjects were randomly chosen for in vivo study. Blood samples were collected over 24 hour period and analyzed by validated HPLC method with UV detection to establish a correlation between in vitro release and in vivo absorption. $f_{2}$ and $f_{1}$ were determined for the time intervals of $5,10,15,20,25,30,45$ and 60 minutes and the obtained values were $65.72,77.38,61.93,53.75$, $55.36,58.59,60.23$ and 61.16 percent for $f_{2}$ and $11.00,4.35,8.30,12.15,5.59,1.82,0.06$ and 0.11 percent for $f_{1}$ at respective time intervals. Mean dissolution times (MDT) for local and reference products were obtained at 7.69 and 9.55 minutes respectively. The values of mean absorption time (MAT) were obtained at 8.27 and 27.96 minutes for local and reference products respectively. For in vitro and in vivo correlation, level A type was also done for both products. In case of level A correlation, a non linear type of relation was established which is typical for immediate release formulations.
\end{abstract}

Key words: In vitro - In vivo correlation, Levofloxacin, Immediate release tablets, Similarity factors.

\section{INTRODUCTION}

The Center for Drug Evaluation and Research (CDER) at the Food and Drug Administration (FDA) released a guidance that set the information which should be provided to CDER to assure continuing product quality and performance characteristics of immediate-release oral solid dosage formulations for specific post-approval changes. ${ }^{1}$ This is commonly called Scale-Up and Post approval Changes for

Correspondence to: Abul Hasnat

Tel. 02-8612069; Fax-02-8615583

E-mail: ahasnat99@yahoo.com

Dhaka Univ. J. Pharm. Sci. 6(2): 113-119, 2007 (December)
Immediate Release (SUPAC IR) that has the major intent to reduce the number of preapproval supplements required for manufacturing changes. According to SUPAC IR guidance, a manufacturer will frequently need to demonstrate that the dissolution profiles of the pre-change product and post-change product are "similar". In Bangladesh all local manufacturers produce generic products by changing manufacturing process(s) or equipment(s) compare to the innovators' products after getting approval from Drug Administration. That's why supplements for Scale-Up and Post approval Changes (SUPAC) are required for those local and generic 
products. For doing so, we made an attempt to establish in vitro - in vivo correlation of both local and innovator's product. We used levofloxacin 250 mg IR film coated tablet as sample drug. SUPAC IR suggests that dissolution profiles may be compared by determining similarity and difference factor $\left(f_{2}\right.$ and $f_{1}$ metric) that are recently introduced by Moor and Flanner. ${ }^{2}$ SUPAC IR also states that an $f_{2}$ value between 50 and $100 \%$ suggests that the two dissolution profiles of local and reference formulations are similar. ${ }^{3}$

Levofloxacin \{(-)-(S)-9-fluoro-2,3-dihydro-3methyl-10-(4-methyl-1-piperazinyl)-7-oxo-7H pyrido [1,2,3-de]-1,4-benzoxazine-6-carboxylic acid hemihydrate $\}$ is a quinoline carboxylic acid derivative with a broad antibacterial activity and effective against a variety of pathogens such as members of the family Enterobacteriaceae, Pseudomonas aeruginosa, and commonly isolated gram-positive organisms such as Staphylococcus aureus and Streptococcus pneumoniae. It has enhanced activity against grampositive organisms. ${ }^{4-6}$ Levofloxacin is rapidly and almost completely absorbed after oral administration and showed excellent tissue penetration by absorbing two-thirds of those in plasma. ${ }^{7,8}$ Peak plasma concentrations are usually attained one to two hours after oral dosing. ${ }^{9,10}$ In Bangladesh a good number of the local manufacturers produce levofloxacin $250 \mathrm{mg}$ tablet. That's why we have chosen levofloxacin as sample drug and compared in-vitro dissolution profiles to establish in vitro-in vivo correlation of a local and innovator's product of levofloxacin.

\section{MATERIALS AND METHODS}

Tablet formulations and dissolution testing. Dissolution testing was performed for both formulations of $250-\mathrm{mg}$ levofloxacin hemihydrate (Tavanic as reference product; lot \# 40D878) from Sanofi-Aventis, UK under the licensing authority of Ortho McNeil, USA and (Trevox ${ }^{\circledR}$ as local product; Batch \# 6075) from Square pharmaceuticals Ltd, Bangladesh. The dissolution testing employed the USP paddle method with $900 \mathrm{ml}( \pm 1 \%)$ of $0.1 \mathrm{~N}$ $\mathrm{HCl}(\mathrm{pH} 2.0)$ at $50 \mathrm{rpm}$ at $37 \pm 0.5^{\circ} \mathrm{C}$ temperatures.
Each tablet was immersed into the media. The distance between the paddle and the bottom of the vessel were set at $25 \pm 2 \mathrm{~mm}$ and the apparatus was operated at $50 \mathrm{rpm}$. After 5, 10, 15, 20, 25, 30, 45 and 60 minutes, $10 \mathrm{ml}$ of solution was withdrawn and replaced by equal amount of $0.1 \mathrm{~N} \mathrm{HCl}$ solution. Then the solutions were filtered through Whatman No.41 filter paper and filtrate was collected both for local and reference products.

Study design and clinical protocol. This was a single center, single dose, randomized study. All volunteers received $250 \mathrm{mg}$ single film coated tablet of both products: Reference formulation (A) or Local formulation (B). Volunteers were randomly divided into two groups (Group-1 and 2) consisting of 6 volunteers in each group. Group-1 received treatment A followed by treatment $\mathbf{B}$ with a seven-day washout period. This sequence of treatment is denoted by $\mathbf{A B}$. Group-2 received treatment $\mathbf{B}$ followed by treatment A after the same washout period. This sequence of treatment is denoted as BA. In the first period, Group-1 received treatment $\mathbf{A}$ and Group-2 received treatment B. In the second period Group-1 received treatment $\mathbf{B}$ and Group-2 received treatment $\mathbf{A}$. This type of study design is known as crossover design in statistical literature. ${ }^{11}$ Each volunteer received the treatment with $250 \mathrm{~mL}$ of water in the morning after overnight fasting. A standard lunch was provided after 4 hours of dosing. Volunteers were monitored constantly for the period of 24 hours by a medical doctor.

Subjects. The mean age \pm SD was $25.63 \pm 1.41$ (24 to 28) years for all volunteers. Their mean body weight and mean height were $69.50 \pm 4.72$ (60 to 75 ) $\mathrm{kg}$ and $1.74 \pm 0.04$ (1.68 to 1.80$) \mathrm{m}$ respectively, giving a mean body mass index (BMI) of $22.89 \pm$ 1.50 (20.50 to 25.0$) \mathrm{kg} / \mathrm{m}^{2}$. Subjects were selected after examining the medical history, physical check up, chest X-ray, ECG, serological screening for infectious disease, and urine analysis. Exclusion criteria included any history of a significant gastrointestinal condition that could potentially impair the absorption or disposition of the study medicine, previous history of allergy to any 
fluoruquinolone, need for any chronic medication (e.g. theophylline, antacid, glibenclamide, phenytoin, iron or vitamins), donation of blood within 30 days preceding the first dose of the study or use of a investigational agent within 30 days of study entry. The volunteers were asked to abstain from taking any medication (including over-the-counter drugs) throughout the study; and from smoking, taking alcohol or caffeine or consuming xanthenecontaining beverages or food for at least 48 hours prior to, and throughout the study. Any incidence of vomiting or any other adverse events found in the volunteer(s) were excluded from the study. They were informed about the risks, benefits, procedures, and aims of the study, as well as their rights as research subjects. The study was conducted according to the Declaration of Helsinki (1964). Each volunteer signed an informed consent document and data collection form before entering the study. Ethical permission was taken to approve the protocol and consent form of this study from Ethical Review Committee of Bangladesh Medical Research Council (BMRC).

Blood sampling. The timing of blood collection was planned according to the previously reported value of time to reach peak serum concentration $\left(T_{\max }\right)$ and serum elimination half-life $\left(t_{1 / 2}\right) .{ }^{12-15}$ An intravenous cannula was placed into the volunteers' forearm vein before drug administration and left in place until the 24-hour blood sample was collected. Venous blood samples were collected before, and at $0.25,0.50,0.75,1.00,1.50,2,3,5,7,9,12$ and 24 hours after drug administration. The blood samples were collected in coded, evacuated tubes, kept 30 minutes for clotting and centrifuged at room temperature (3000 rpm for 15 minutes). The serum was collected in coded eppendorf tubes and serum protein was separated by precipitation with ethanol followed by centrifugation at $10,000 \mathrm{rpm}$ for 5 minutes. The serum was collected and stored at $80^{\circ} \mathrm{C}$ until further analysis.

Data Analysis. The area under the plasma concentration-time curve to $24 \mathrm{hr}$ (AUC ${ }_{0-24}$ ) was determined by the trapezoidal rule, and the area under the serum concentration-time curve extrapolated to infinity $\left(\mathrm{AUC}_{0-\infty}\right)$ was calculated according to the following formula:

$\mathrm{AUC}_{0-\infty}=\mathrm{AUC}_{0-\mathrm{t}}+\mathrm{C}_{\mathrm{t}} / \mathrm{K}_{\mathrm{el}}$, where $\mathrm{C}_{\mathrm{t}}$ is the last quantifiable serum level. ${ }^{16}$

The percent of drug absorbed was calculated by means of model dependent techniques such as Wagner-Nelson procedure. According to Wagner Nelson equation,

$$
\frac{A_{t}}{A_{0}}=\frac{C_{t}+K_{e l} \bullet A U C_{0}^{t}}{K_{e l} \bullet A U C_{0}^{\infty}} \quad \text {------- } \quad(\text { Equation-1) }
$$

Here, $\frac{A_{t}}{A_{0}}$ denotes the fraction of drug absorbed at time $t, C_{t}$ is the plasma drug concentration at time $t$, $\mathrm{K}_{\mathrm{el}}$ is elimination rate constant, $A U C_{0}^{t}$ and $A U C_{0}^{\infty}$ are the area under the plasma concentration - time profile curve at time $t$ and $\alpha$ respectively.

Similarity factor $\left(f_{2}\right)$ and difference factor $\left(f_{1}\right)$ were also determined by using the equation developed by Moor and Flanner (equations 2 and 3).

$f_{2}=50 \log \left[\left\{1+1 / \mathrm{n} \sum_{t=1}^{n}\left(\mathrm{R}_{\mathrm{t}}-\mathrm{T}_{\mathrm{t}}\right)^{2}\right\}^{-0.5} \times 100\right]---\quad($ Eq.-2)

$f_{1}=\left[\left\{\sum_{t=1}^{n}\left|\mathrm{R}_{\mathrm{t}}-\mathrm{T}_{\mathrm{t}}\right| / \sum_{t=1}^{n} \mathrm{R}_{\mathrm{t}}\right\} \times 100\right]--------\quad($ Eq.-3)

Where $R_{t}$ and $T_{t}$ are the percent drug dissolved at each time point for the reference and test products, respectively; $\mathrm{n}$ is the number of dissolution sample times and $t$ is the time points for collecting dissolution samples. ${ }^{2,17}$

The Mean Dissolution Time ( $\mathrm{MDT}_{\text {in vitro }}$ ), Mean Absorption Time ( $\mathrm{MAT}_{\text {in vivo }}$ ) were also calculated both for local and reference formulations by using equations (4) and (5). ${ }^{17,18}$

$\mathrm{MDT}_{\text {in vitro }}=\sum_{t=1}^{n} t_{\text {mid }} \Delta M / \sum_{t=1}^{n} \Delta M$----- (Eq. 4)
$\mathrm{MAT}_{\text {in vivo }}=\sum_{t=1}^{n} t_{\text {mid (in vivo) }} \Delta M_{\text {in vivo }} / \sum_{t=1}^{n} \Delta M_{\text {in vivo }}$-- (Eq. 5)

Here, $t_{\text {mid }}$ is the time at mid point between $i$ and $i-1, \Delta M$ is the additional amount of drug dissolved between $i$ and $i-1, \Delta M_{\text {in vivo is the additional amount }}$ of drug absorbed between $i \&$ i- 1 . 


\section{RESULTS AND DISCUSSION}

The dissolution results for individual tablets are listed in Table 1 and presented graphically in the Figure 1. From the graphical presentation it was observed that the dissolution pattern of Reference $\left(\right.$ Tavanic $^{\circledR}$ ) product was almost similar to that of Local $\left(\right.$ Trevox $\left.^{\circledR}\right)$ product. Similarity factors $\left(f_{2}\right)$ and difference factors $\left(f_{1}\right)$ for reference and local products are also presented in Table 1. For both products the percent of drug released was calculated from dissolution profiles \& percent of drug absorbed for both reference and local formulations were obtained from the equation 1 and have been shown in Table 2 .
Mean levofloxacin plasma concentrations through 24 $\mathrm{hr}$ for reference product and local formulation were found similar. Mean area under the plasma concentration-time curve (AUC) for local product $\left(\right.$ Trevox $^{\circledR}$ ) versus reference product $\left(\right.$ Tavanic $^{\circledR}$ ) is given in the Figure 2 and indicates that reference formulation $\left(\right.$ Tavanic $^{\mathbb{B}}$ ) has similar bioavailability $\left(\mathrm{F}_{\text {relative }}=1.21\right)$ to the marketed product $\left(\right.$ Trevox $\left.^{\circledR}\right)$. Similar type of curve was obtained from percent drug absorbed versus time plot for both products (Figure 3). The values of $\mathrm{MDT}_{\text {in vitro }}$ and $\mathrm{MAT}_{\text {in vivo }}$ were also presented in the table 3 both for local and reference formulation.

Table 1. Dissolution profile for Local and Reference product of Levofloxacin $250 \mathrm{mg}$ IR Tablets.

\begin{tabular}{|c|c|c|c|c|c|c|c|c|}
\hline \multicolumn{9}{|c|}{ Percent Released (\%) } \\
\hline \multicolumn{9}{|c|}{ Local (test) Product } \\
\hline Sample & $5 \mathrm{~min}$ & $10 \mathrm{~min}$ & $15 \mathrm{~min}$ & $20 \mathrm{~min}$ & $25 \mathrm{~min}$ & $30 \mathrm{~min}$ & $45 \mathrm{~min}$ & $60 \mathrm{~min}$ \\
\hline 1 & 43.82 & 60.94 & 86.69 & 101.55 & 100.87 & 101.46 & 101.55 & 99.85 \\
\hline 2 & 43.59 & 58.46 & 92.42 & 98.38 & 99.51 & 99.47 & 99.50 & 98.83 \\
\hline 3 & 44.04 & 67.92 & 97.42 & 100.64 & 100.64 & 100.62 & 100.64 & 97.72 \\
\hline 4 & 41.79 & 59.80 & 93.10 & 97.92 & 97.93 & 97.90 & 97.93 & 100.63 \\
\hline 5 & 43.59 & 58.46 & 90.73 & 99.06 & 99.06 & 99.01 & 99.06 & 98.16 \\
\hline 6 & 41.91 & 60.14 & 88.26 & 96.79 & 96.79 & 96.75 & 96.79 & 100.51 \\
\hline Mean & 43.12 & 60.96 & 91.44 & 99.06 & 99.13 & 99.20 & 99.24 & 99.28 \\
\hline$\pm \mathrm{SD}$ & 1.00 & 3.55 & 3.81 & 1.76 & 1.57 & 1.73 & 1.74 & 1.23 \\
\hline SE & 0.17 & 0.59 & 0.64 & 0.29 & 0.26 & 0.29 & 0.29 & 0.20 \\
\hline \multicolumn{9}{|c|}{ Reference Product } \\
\hline 1 & 37.97 & 58.32 & 84.88 & 88.85 & 91.35 & 96.43 & 99.49 & 99.51 \\
\hline 2 & 39.32 & 58.33 & 84.43 & 87.61 & 95.28 & 95.66 & 100.84 & 100.87 \\
\hline 3 & 36.84 & 58.20 & 84.43 & 84.12 & 92.00 & 97.78 & 99.72 & 99.74 \\
\hline 4 & 38.53 & 59.00 & 80.38 & 87.36 & 93.25 & 98.35 & 98.98 & 98.04 \\
\hline 5 & 37.63 & 58.21 & 84.88 & 87.28 & 94.42 & 97.23 & 98.73 & 100.18 \\
\hline 6 & 39.99 & 57.77 & 84.09 & 86.93 & 95.28 & 98.92 & 98.04 & 98.04 \\
\hline Mean & 38.38 & 58.30 & 83.85 & 87.03 & 93.60 & 97.39 & 99.30 & 99.39 \\
\hline$\pm \mathrm{SD}$ & 1.15 & 0.40 & 1.72 & 1.57 & 1.68 & 1.21 & 0.96 & 1.15 \\
\hline SE & 0.19 & 0.07 & 0.29 & 0.26 & 0.28 & 0.20 & 0.16 & 0.19 \\
\hline$f_{2}(\%)$ & 65.72 & 77.38 & 61.93 & 53.75 & 55.36 & 58.59 & 60.23 & 61.16 \\
\hline$f_{1}(\%)$ & 11.00 & 4.35 & 8.30 & 12.15 & 5.59 & 1.82 & 0.06 & 0.11 \\
\hline
\end{tabular}

$\mathrm{SD}=$ Standard deviation, $\mathrm{SE}=$ Standard error,$f_{1}=$ Difference factor, $f_{2}=$ Similarity factor.

\section{In vitro - In vivo relationship}

Determination of Level A correlation. Level A correlation is the highest category of correlation and represents a point-to-point (1:1) relationship between in vitro dissolution rate and in vivo input rate of the drug from the dosage form. ${ }^{19}$ For level A correlation, percent of drug released from immediate release film coated tablet was determined, for both reference and local products, according to compendia dissolution method using Apparatus II (paddle apparatus) which has been discussed earlier and the results are presented in the Table 1.

Percent of drug absorbed was calculated from the mean serum drug concentrations, using Wagner Nelson equation (Equation-1) for both reference and local products (Table 2). Then the values of percent of drug released were plotted against the percent of drug absorbed to find out the relationship (Figure 4). 
Table 2 Mean percent of drug released and absorbed for both local and reference products.

\begin{tabular}{ccccc}
\hline \multirow{2}{*}{$\begin{array}{c}\text { Time } \\
\text { (hr) }\end{array}$} & \multicolumn{2}{c}{ Local product } & \multicolumn{2}{c}{ Reference product } \\
\cline { 2 - 5 } & $\begin{array}{c}\text { \% drug } \\
\text { released }\end{array}$ & $\begin{array}{c}\text { \% drug } \\
\text { absorbed }\end{array}$ & $\begin{array}{c}\text { \% drug } \\
\text { released }\end{array}$ & $\begin{array}{c}\text { \% drug } \\
\text { absorbed }\end{array}$ \\
\hline 0.25 & 91.44 & 40.14 & 83.85 & 33.87 \\
0.50 & 99.20 & 83.53 & 97.39 & 62.17 \\
0.75 & 99.24 & 106.59 & 99.30 & 89.74 \\
1.00 & 99.28 & 123.00 & 99.39 & 114.00 \\
\hline
\end{tabular}

Table 1 describes the similarity factors $\left(f_{2}\right)$ for 5 , $10,15,20,25,30,45$ and 60 minutes and the obtained values were $65.72,77.38,61.93,53.75$, $55.36,58.59,60.23$ and 61.16 percent, respectively. As, similarity factors $\left(f_{2}\right)$ were within the acceptable range of $50 \%$ to $100 \%$, local formulation is similar to reference formulation. ${ }^{3}$

Difference factors $\left(f_{1}\right)$ were obtained $11.00,4.35$, $8.30,12.15,5.59,1.82,0.06$ and 0.11 percent for the same time intervals. The values for $f_{1}$ were also within the acceptable range (less than $15 \%)^{3}$

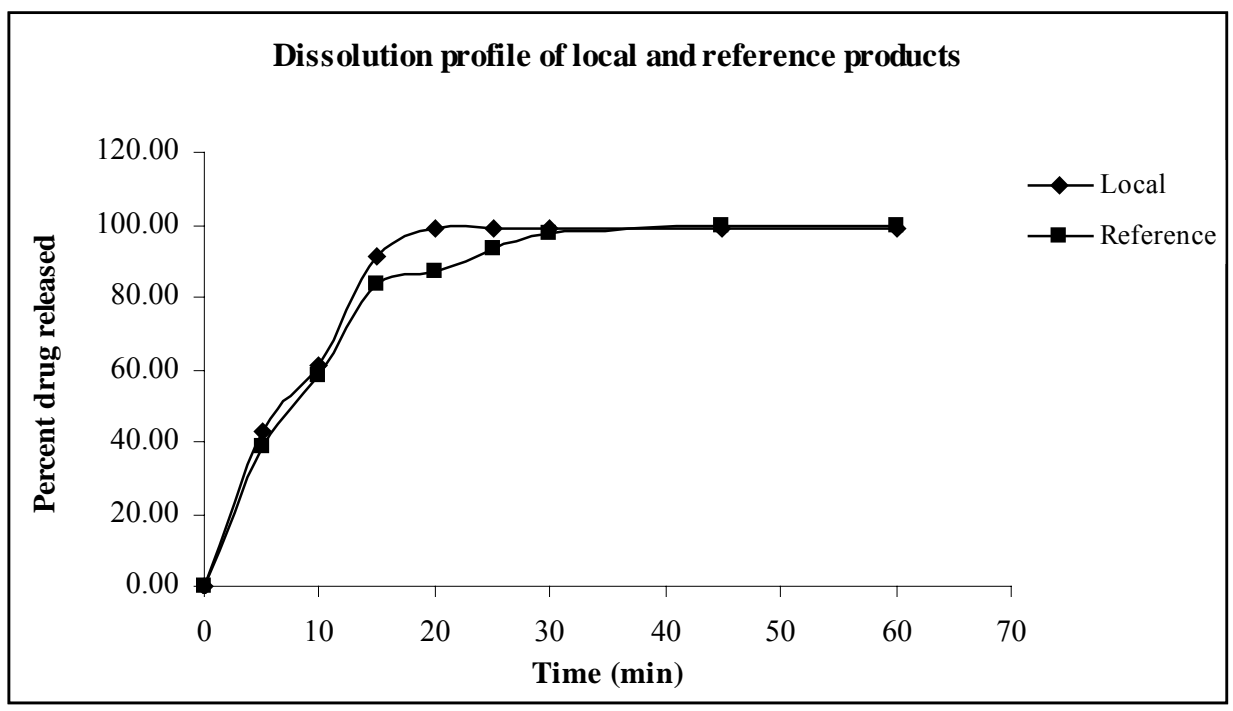

Figure 1. Comparison of mean dissolution rate between Local (Trevox) and Reference (Tavanic) products.

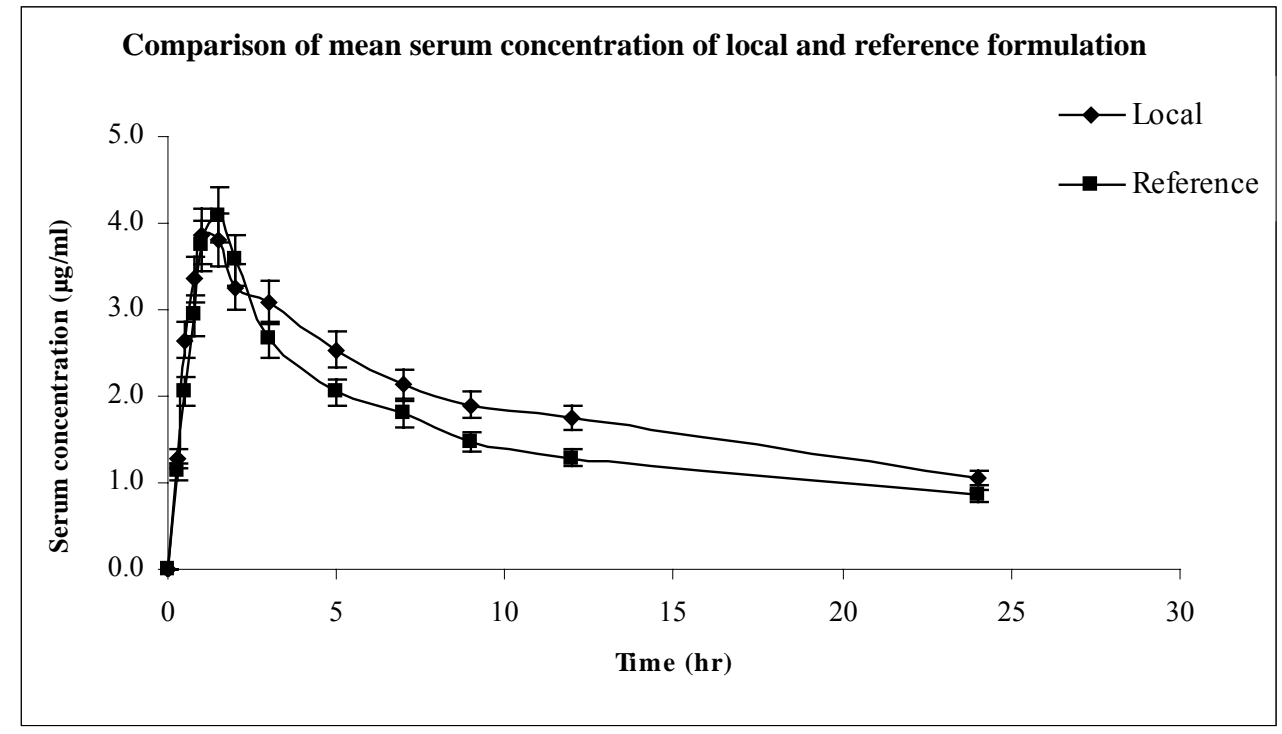

Figure 2. Mean plasma concentrations of levofloxacin at different time intervals of Local (Trevox) and Reference (Tavanic) formulation. 
From the table 3, the mean absorption time (MAT) for local formulation is shorter due to low mean dissolution time (MDT) and opposite circumstance for reference formulation.

Percent of drug absorbed from local product and reference product have followed similar pattern and they are very close to each other in our study (Figure 2 and 3). That's why initially we observed a gradual increase of the percent of drug absorbed both for local and reference product with a rapid increase in the terminal phase (Figure 4).

Table 3. The values of $\mathrm{MDT}_{\text {in vitro }}$ and $\mathrm{MAT}_{\text {in vivo, }}$ both for local and reference formulation.

\begin{tabular}{lcc}
\hline Formulation & $\begin{array}{c}\text { MDT }_{\text {in vitro }} \\
\text { (minute) }\end{array}$ & $\begin{array}{c}\text { MAT }_{\text {in vivo }} \\
\text { (minute) }\end{array}$ \\
\hline Local & 7.69 & 8.27 \\
Reference & 9.55 & 27.96 \\
\hline
\end{tabular}

MDT $=$ Mean Dissolution Time, MAT $=$ Mean Absorption Time

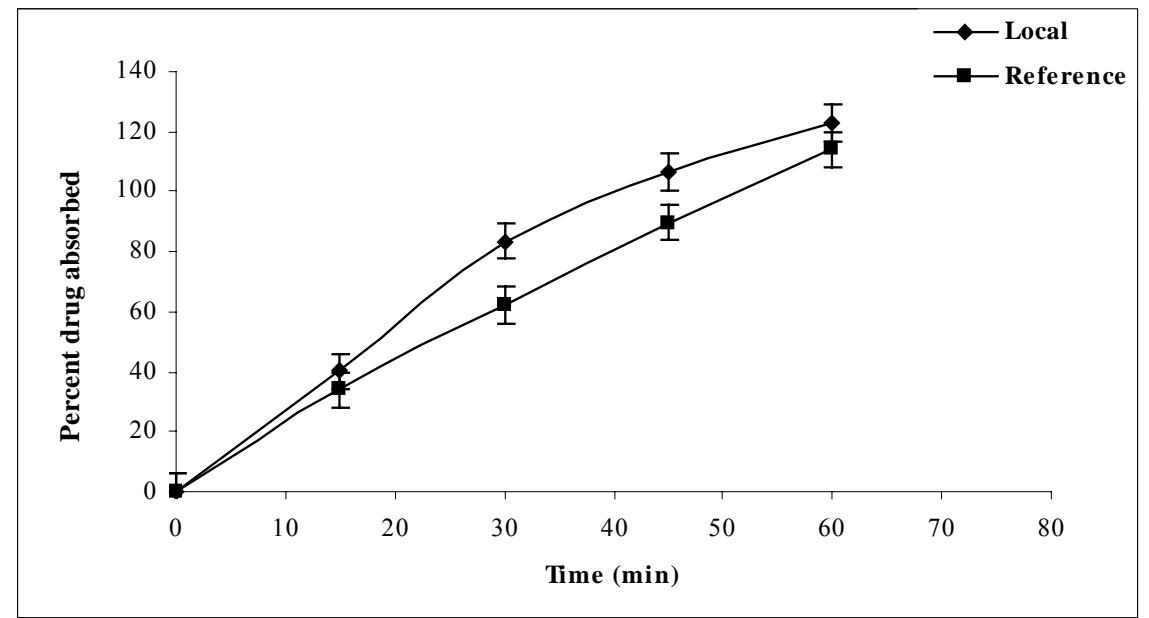

Figure 3. Mean Wagner-Nelson plot for Local (Trevox) and Reference (Tavanic) products after administration of levofloxacin to 12 healthy male volunteers.

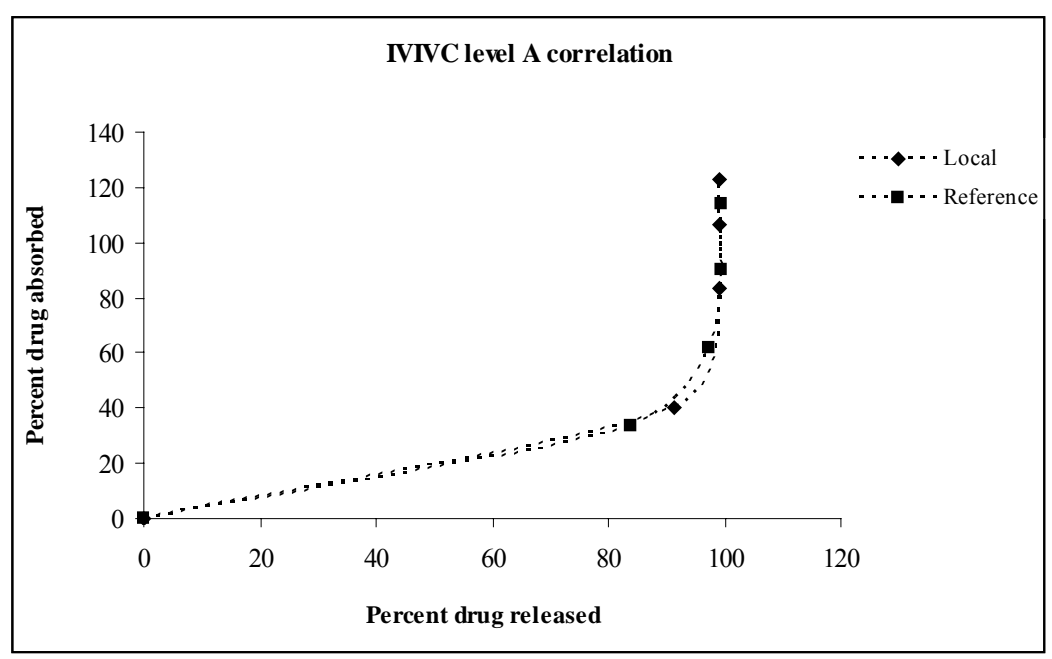

Figure 4. Non linear Level A correlations (IVIVC) for both local and reference product

In level A correlation, we might conclude that there is no linear correlation between percent of drug release \& percent of drug absorbed for both products.
Levofloxacin film coated tablet is an Immediate Release formulation. As dissolution is not a ratelimiting step in IR products, the fraction of drug 
absorbed against the fraction of drug released profile would be non-linear type which was obtained in our present study. Since absorption cannot "keep up" with dissolution, a nonlinear relationship between the fractions of drug absorbed and the fractions of drug released was obtained. So it may be concluded that the In vitro - In vivo correlation is well established and justified for both local (test) and reference formulations by level A correlation.

\section{ACKNOWLEDGEMENTS}

The authors would like to express their gratitude to SQUARE Pharmaceuticals Ltd. and NOVO Healthcare and Pharma Ltd, Bangladesh, for their support by donating necessary chemicals.

\section{REFERENCES}

1. Federal Register, Part V, Vol. 60, No, 230. 1995. 6163861643.

2. Moore, J.W. and Flanner, H.H. 1996. Mathematical Comparison of curves with an emphasis on in vitro dissolution profiles. Pharm. Tech. 20(6), 64-74.

3. Guidance for Industry. 1995. Immediate Release Solid Oral Dosage Forms, Scale-Up and Post approval Changes: Chemistry, Manufacturing, and Controls, In Vitro Dissolution Testing, and In vivo Bioequivalence Documentation. FDA, CDER.

4. Dholakia, N., Rolston, K.V.I., Ho, D.H., Le Blanc, B. and Bodey, G.P. 1994. Susceptibilities of bacterial isolates from patients with cancer to levofloxacin and other quinolones. Antimicrob Agents Chemother. 38, 848-852.

5. Fu, K.P., Lafredo, S.C., Foleno, B., Isaacson, D.M., Barrett, J.F., Tobia, A.J. and Rosenthale, M.E. 1992. In vitro and in vivo antibacterial activities of levofloxacin (1-ofloxacin), an optically active ofloxacin, Antimicrob. Agents Chemother. 36, 860-866.

6. Marshall, S.A., and Jones, R.N. 1993. The in vitro activity of DU-6859a, a new fluropropyl quinolone. Antimicrob. Agents Chemother. 37, 2747-2753.

7. Johnson, J.H., Cooper, M.A., Andrews, J.M. and Wise, R. 1992. Pharmacokinetics and inflammatory fluid penetration of sparfloxacin. Antimicrob. Agents Chemother. 36, 24442446.
8. Nye, K., Shi, Y.G., Andrews, J.M., Ashby, J.P. and Wise. R. 1989. The in vitro activity, pharmacokinetics and tissue penetration of temafloxacin. J. Antimicrob. Chemother. 24, 415-424.

9. Wolfson, J.S. and Hooper, D.C. 1989. Comparative pharmacokinetics of ofloxacin and ciprofloxacin. Am J Med. 87 (suppl 6C), 31-36.

10. Fish, D.N. and Chow, A.T. 1997. The clinical pharmacokinetics of levofloxacin. Clin Pharmacokinetic. 32, 101-119.

11. Jones, B., Kenward, G. M. 2003. Design and Analysis of Cross-Over Trials. Second edition. Champman and Hall/CRC, ISBN 0412606402.

12. Food and Drug Administration. 1999. Tequin Tablets (gatifloxacin), Tequin Injection (gatifloxacin). Washington, DC: Department of Health and Human Services.

13. Hutchinson, T.A., Shahan, D.R. and Anderson, M.L. 2001. Drugdex System. Englewood, CO: Micromedex.

14. Nakashima, M., Uematsu, T. and Kosuge, K. 1995. Single and multiple-dose pharmacokinetics of AM-1155, a new 6fluoro-8-methoxy quinolone, in humans. Antimicrob Agents Chemother. 39, 2635-2640.

15. Liang, H., Kays, M. and Sowinski, K. 2002. Separation of levofloxacin, ciprofloxacin, gatifloxacin, moxifloxacin, trovafloxacin and cinoxacin by high performance liquid chromatography: application to levofloxacin determination in human plasma. J. Chromatogr. 772, 53-63.

16. Gibaldi, M. and Perrier, D. 1982. Pharmacokinetics, 2nd ed. New York. Dekker. pp. 433-434.

17. Polli, J.E., Rekhi, G.S., Augsburger L.L., and Shah V.P. 1997. Methods to compare dissolution profiles and a rationale for wide dissolution specifications for metoprolol tartrate tablets. J. Pharm. Sci. 86, 690-700.

18. Emami, J. 2006. In vitro In vivo correlation: From Theory to Applications. J. Pharm Pharmaceut Sci. (www.cspsCanada. org) 9, 31-52.

19. Guidance for industry. 1997. Extended release oral dosage forms: development, evaluation and application of an in vitro/in vivo correlation. FDA, CDER. 